DOI 10.5216/ag.v4i12.12784

\title{
POLÍTICA DE DESENVOLVIMENTO, PRODUÇÃO CAMPONESA E OS DESAFIOS DA AGROECOLOGIA ${ }^{1}$
}

\author{
DEVELOPMENT POLICY, PEASANT PRODUCTION AND THE \\ CHALLENGES OF AGROECOLOGY
}

\section{POLÍTICA DE DESARROLLO, LA PRODUCCIÓN CAMPESINA Y LOS DESAFÍOS DE LA AGROECOLOGÍA}

\author{
Juliano Luis Borges \\ Doutorando em Ciências Sociais pela Pontifícia Universidade Católica de São Paulo (PUC/SP) \\ Professor da Universidade de Cuiabá (UNIC) \\ Av. Virgilio Favetti, nº 1.200 S, Vila Alta, Tangará da Serra-MT / CEP 78.300-000 \\ E-mail: jlb_br@yahoo.com.br \\ Sandro Benedito Sguarezi
Doutorando em Ciências Sociais pela Pontifícia Universidade Católica de São Paulo (PUC/SP) Professor da Universidade do Estado de Mato Grosso (UNEMAT)
Rodovia MT - 358, Km 07, Jardim Aeroporto, Tangará da Serra - MT / CEP 78.300-000
E-mail: sandrosguarezi@terra.com.br

\begin{abstract}
Resumo
O processo de modernização da agricultura intensificou a homogeneização dos padrões de produção em detrimento às características locais dos agricultores tradicionais. Isso levou a uma desagregação de valores simbólicos de reprodução social e cultural baseados no vínculo com a terra. A lógica tradicional de produção considerava que a função da terra era suprir as necessidades básicas de subsistência, em articulação com um excedente comercializável. Para o Estado, comprometido com o avanço do sistema capitalista, esses camponeses não possuíam relevância do ponto de vista econômico e necessitavam do incremento de novas técnicas para se inserirem no circuito mercantil, com o aumento da renda na unidade de produção e o consequente endividamento. Assim, ocorreram conflitos de representações entre duas lógicas distintas, que acarretaram graves consequências para o campesinato brasileiro. Nesse contexto, a agroecologia se apresenta como uma perspectiva teórica e uma estratégia alternativa de resistência do campesinato para continuar produzindo e vivendo no campo.
\end{abstract}

Palavras-chave: modernização, campesinato, agroecologia.

\footnotetext{
${ }^{1}$ Este trabalho, modificado parcialmente, foi apresentado no $2^{\circ}$ Encontro Internacional de Ciências Sociais, realizado na Universidade Federal de Pelotas (UFPel), em 2010.
} 


\section{Abstract}

The process of modernization of agriculture has increased the homogenization of production patterns to the detriment of local characteristics of traditional farmers. This has led to a breakdown of symbolic values of cultural and social reproduction based on relation to the land. The traditional logic of production considered that the function of the land was to supply the basic needs of subsistence, in conjunction with a marketable surplus. For the Government, in commit to the advancement of the capitalist system, these peasants had no relevance in terms of economic growth and needing new techniques to be increased in order to fit into the trading circuit, with increased income in the production unit and the resulting debt. Thus, there were representations conflicts between two logics, which led to serious consequences for the Brazilian peasantry. In this context, agroecology is presented as a theoretical perspective and an alternative of resistance from the peasantry to continue producing and living in the countryside.

Keywords: modernization, peasantry, agroecology.

\section{Resumen}

El proceso de modernización de la agricultura ha aumentado la homogeneización de los modelos de producción en detrimento de las características locales de los agricultores tradicionales. Esto llevó a una ruptura de los valores simbólicos de la reproducción cultural y social basado en la vinculación con la tierra. La lógica tradicional de producción considerado que la función de la tierra era para abastecer las necesidades básicas de subsistencia, em conjunción a un excedente comercializable. Para el Estado, comprometido con el adelanto del sistema capitalista, estos campesinos no tenían ninguna relevancia en términos de crecimiento económico y tenían necesidad de nuevas técnicas para entrar en el circuito comercial, con un ingreso mayor en la unidad de producción y la deuda consiguiente. Así, se produjeron conflictos de representaciones entre dos distintos logicas, que dio lugar a graves consecuencias para los campesinos brasileños. En este contexto, la agroecología se presenta como una perspectiva teórica y una estrategia alternativa de la resistencia de los campesinos a seguir con la producción y vida en el campo.

Palabras-clave: modernización, campesinos, agroecología.

\section{Introdução}

A modernização da agricultura corresponde a um longo processo desencadeado pela apropriação capitalista das terras e da produção agrícola. No Brasil, a modernização começa a se delinear a partir do pós-guerra, e se consolidou no período da ditadura militar através de políticas de estímulo ao crescimento econômico no país. A lógica desenvolvimentista do Estado, centrada nos interesses do capitalismo industrial e financeiro, buscou a homogeneização dos padrões de produção, independente das 
relações sociais e produtivas existentes, principalmente da pequena produção tradicional

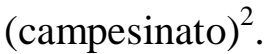

Por meio de uma análise exploratória, calcada em referenciais que discutem o processo de transformação da agricultura brasileira, este trabalho traz elementos para compreensão da modernização da agricultura e desagregação de valores simbólicos de reprodução social e cultural dos camponeses. Além disso, é iniciada uma discussão sobre a agroecologia como alternativa de articulação entre trabalho, produção, saber tradicional e desenvolvimento local.

As consequências da "modernização conservadora" nos âmbitos sociais, econômicos, políticos e ambientais evidenciaram os limites e contradições do modelo de produção implementado pelo Estado. No contexto de esgotamento desse modelo, a agroecologia surge como uma alternativa e uma tecnologia social para camponeses e agricultores familiares construírem possibilidades de organização do trabalho e produção e gerarem condições de fixação no campo. Isso significa iniciar uma transição da matriz produtiva e criar espaços de comercialização e incremento de renda. Essas mudanças passam pela redefinição do papel das políticas públicas para os pequenos produtores, que trazem em seu escopo elementos teóricos e práticos para o desenvolvimento sustentável.

\section{A modernização da agricultura no Brasil}

A modernização da agricultura brasileira é um processo que está intimamente ligado ao modo de produção capitalista e a forma racional/positivista de tecnificação científica (GUEVARA; HOEFFEL; VIANA, 1998). Essa visão de ciência contribuiu para o surgimento de um padrão de desenvolvimento expresso na acumulação material, o que o identifica com a noção de crescimento. "[...] desenvolvimento técnico-científico $\rightarrow$ desenvolvimento sócio-econômico $\rightarrow$ progresso e crescimento" (ALMEIDA, 1997, p. 18).

${ }^{2} \mathrm{O}$ texto não vai se aprofundar na análise da agricultura familiar incorporada ao mercado pelas estratégias de integração à agroindústria. Tampouco vai aprofundar o debate na exclusão dos médios e grandes agricultores que nesse período perderam suas propriedades por causa dos elevados índices de endividamento junto aos bancos e às empresas multinacionais que financiaram a agricultura empresarial. 
No início do século XX, o otimismo da comunidade agronômica internacional diante das descobertas e da aplicação do "quimismo" de Justus Von Liebig levaram ao auge daquilo que podemos qualificar como inicio da moderna agricultura, consagrada pelo padrão químico, motomecânico e genético, que no final da década de 60 explode na chamada "Revolução Verde", priorizando o aumento da produtividade e interferindo nos padrões culturais e de desenvolvimento, principalmente nos países de terceiro mundo (EHLERS, 1996).

A modernização da agricultura consolidou no campo, de forma hegemônica, o modo de produção especificamente capitalista. Esse processo induzido no período pós Segunda Guerra Mundial transformou a base técnica da agricultura no país, inserindo um novo padrão de produção e novas formas de relações sociais.

Essa modernização, que se fez sem que a estrutura da propriedade rural fosse alterada, teve, no dizer dos economistas, 'efeitos perversos': a propriedade tornou-se mais concentrada, as disparidades de renda aumentaram, o êxodo rural acentuou-se, aumentou a taxa de exploração da força de trabalho nas atividades agrícolas, cresceu a taxa de auto-exploração nas propriedades menores, piorou a qualidade de vida da população trabalhadora do campo. Por isso, os autores gostam de usar a expressão 'modernização conservadora' (PALMEIRA, 1989, p. 87).

A estrutura político-econômica de dominação, construída desde o período colonial, foi mantida sob a tutela do progresso técnico na agricultura. A melhoria da produtividade agrícola se efetivou nas grandes e médias propriedades que conseguiram sobreviver a custas de ampliar a área plantada e a escala de produção via mecanismos de mercado. Grande parcela da população rural, residente em pequenas quantidades de terra, sofreu com as consequências negativas, provocadas pela miserabilidade, proletarização e êxodo rural. Apesar dessa situação, o Estado teve um papel ativo na propagação da ideologia do progresso e proporcionou a conservação de todo um aparato de poder secular em nome da modernização e crescimento econômico do país.

A apropriação capitalista da agricultura, apoiada numa visão tecnicista da "Revolução Verde", e sustentada por políticas estatais de financiamento, assistência técnica e extensão rural, possibilitou uma nova dinâmica no campo brasileiro. A "Revolução Verde" estabeleceu inovações que intensificaram de maneira bastante contundente o modo de produzir e o modo de se relacionar com a terra; os chamados "pacotes tecnológicos" revolucionaram o modo de produzir e transformaram a 
realidade do campo numa arena de negócios. A ideologia propagada pela "Revolução Verde" pregava o fim da falta de alimentos, mas paradoxalmente, ao invés de erradicar a fome no mundo, ocorreu o fortalecimento das corporações agroindustriais, a degradação ambiental e a exclusão social, decorrentes da concentração de capital e de terras, do alto preço dos insumos e maquinários, seguido por um elevado endividamento agrícola. A conjugação desses fatores, contraditoriamente, provocou a ampliação dos problemas no campo brasileiro, pois foram as bases da expansão capitalista na agricultura.

[...] nos países, como o Brasil, em que a 'Revolução Verde' não foi acompanhada de uma reforma agrária, mas apenas um sucedâneo desta, resultou graves consequências, tanto de ordem econômica como principalmente sociais. Nestes países a 'Revolução Verde' foi apenas um instrumento de 'modernização conservadora' que ajudou a aprofundar a internacionalização da economia e a agravar a dependência (BRUM, 1985, p. 71-72).

O desenvolvimento da matriz de produção moderna provocou mudanças significativas, percebidas na estratégia de integração da agricultura à indústria como um ramo em sua cadeia produtiva. O progresso técnico não foi acompanhado dos avanços sociais requeridos, tampouco de técnicas de gestão estratégicas. Isso elevou o grau de dependência do agricultor brasileiro.

Antes da "Revolução Verde", a produção agrícola era condicionada por fatores de "ordem natural" - integração das práticas agrícolas aos ciclos naturais, num processo de relação "harmoniosa" do homem com a natureza - e pela utilização de ferramentas e insumos produzidos na própria propriedade.

São, portanto, dois processos: um de destruição da economia natural, pela retirada progressiva dos vários componentes que asseguravam a 'harmonia' da produção assentada na relação homem-natureza (e suas contradições); e o outro, de uma nova síntese, de recomposição de uma outra 'harmonia' também permeada por novas contradições - baseada no conhecimento e no controle cada vez maior da natureza e na possibilidade de reprodução artificial das condições naturais da produção agrícola. A esta passagem se denomina industrialização da agricultura (GRAZIANO DA SILVA, 1996, p. 03, grifo do autor).

As condições naturais de produção passaram a ser subordinadas ao avanço técnico de capitalismo tendo como parâmetro o controle artificial de todo o processo. 
As transformações na produção agrícola não ficaram restritas à aplicação técnica, mas afetaram de maneira significativa as relações sociais que a permeava. Ampliaram o êxodo rural e geraram proletarização dos agricultores tradicionais nos grandes complexos agroindustriais (CAIs). Os CAIs podem ser entendidos como resultado da intensificação da modernização nos anos 60 , pois sua emergência se deu através da produção industrial de máquinas e insumos para a agricultura (KAGEYAMA, 1990). Por meio dos CAIs foi possível a estabilização do setor industrial de máquinas e insumos, além de elevar o grau de dependência da agricultura à agroindústria e ao mercado de exportações.

A política de crédito vinculava o financiamento para a produção de monoculturas (milho, soja, algodão, etc.), a ser processada internamente pelas agroindústrias, ou exportada com preços variáveis de acordo com o mercado internacional (commodities ${ }^{3}$ ). $\mathrm{O}$ incentivo a essa produção atendia aos interesses desenvolvimentistas dos setores agrários dominantes; assim este se tornou fundamental para a economia, uma vez que os superávits da balança comercial do país dependiam cada vez mais do financiamento desse modelo cada vez mais insustentável.

Nesse contexto, a campesinato não estaria contribuindo para a potencialização da economia nacional, o qual, na visão hegemônica, deveria ser integrado ao processo desenvolvimentista. As políticas de crédito e extensão rural foram importantes para desagregar uma lógica de produção regida por parâmetros diferenciados daqueles incentivados pelo governo e pelo mercado. Assim, o Estado impôs um modelo extensionista centrado em pacotes tecnológicos para difundir a modernização da agricultura e consolidar novas relações de produção, desconsiderando a cultura campesina.

\section{A lógica produtivista e o saber camponês}

O difusionismo tecnológico contido nos programas de assistência técnica e extensão rural influenciaram a introdução de novas práticas e relações sociais no campo 
brasileiro. Essas políticas foram determinadas pelos interesses do modo de produção hegemônico. As relações sociais capitalistas e o aparato técnico desenvolvido foram as bases que conformaram o paradigma de extensão rural exigido pelo modelo econômico dominante. Essa foi a estratégia encontrada para integrar a agricultura à agroindústria e ao processo de crescimento econômico do país.

A transmissão do saber técnico na agricultura provocou grande impacto, principalmente na agricultura camponesa, considerada atrasada para a economia do país. O sentido das políticas governamentais era romper com esse "modelo estagnado" e promover sua inserção no circuito mercantil que vinha se desenvolvendo. Amparada por certo conhecimento científico, essa prática buscou reproduzir as relações capitalistas apoiadas pelo Estado, tendo como referência o modelo extensionista norte-americano (CAPORAL; COSTABEBER, 2001). A extensão rural, aliada à disponibilização de crédito rural (vinculado aos "pacotes" modernos), transformava-se na realizadora da modernização da agricultura.

O avanço da modernidade, no Brasil, na década de 70, exigiu instrumentos mais eficientes e uma articulação mais eficaz. Para atender a essa necessidade, o governo brasileiro criou em 1971, a Empresa Brasileira de Pesquisa Agropecuária (EMBRAPA). A atuação dessa organização, de fato, acaba sendo influenciada, direta ou indiretamente, pelos centros internacionais. [...] Também na década de 70, e pelas mesmas razões, foi estruturado e dinamizado o sistema nacional de assistência técnica e extensão rural, através da criação da EMBRATER - Empresa Brasileira de Assistência Técnica e Extensão Rural - vinculada ao Ministério da agricultura. O sistema se completa, estendendo-se aos diversos Estados da nação, em cada um deles, da sua respectiva EMATER - Empresa de Assistência Técnica e Extensão Rural (BRUM, 1985, p. 68-69).

Esse sistema tinha a função de estabelecer novas diretrizes para a produção por meio de atividades que contribuíssem para o processo de transição do campesinato, considerado o setor atrasado da economia para outro de base tecnicista moderna. A extensão rural foi criada com o objetivo de disseminar a agricultura moderna, que encontrava, na lógica tradicional de produção, um entrave para sua expansão. A economia tradicional camponesa era pautada por princípios totalmente diferenciados daqueles propostos pela acumulação capitalista no campo.

\footnotetext{
${ }^{3}$ São produtos de base - matérias primas, geralmente in natura - com baixo valor agregado, com preços fixados pelo mercado internacional e visam atender às demandas de exportação.
} 
Nas práticas e discursos dos camponeses estavam expressas as significações de si próprios e do mundo, construídas através de relações com o real - sua representação ${ }^{4}$. A representação é o mecanismo que, por meio da experiência, atribui sentido à realidade social. Através da representação surgem visões de mundo e projetos determinados, que integram e formam, num fluxo constante, um conjunto de elementos - símbolos e signos -, atuantes não apenas no plano discursivo (subjetivo), mas, essencialmente, nas práticas sociais (objetivas e materiais).

A cultura tradicional ${ }^{5}$ camponesa configura um elemento importante para a consolidação de um sistema de produção específico, o qual é regido por padrões de trabalho que garantem a autonomia nas estratégias adotadas para a manutenção da unidade econômica familiar. "La cultura tradicional es una realidad sui generis, dotada de su propia dinámica específica. Un bajo nivel de tecnología agrícola y de estabilidad del asentamiento campesino representa, talvez, sus fundamentos más importantes" (DOBROWOLSKI, 1979, p. 252).

A organização econômica da propriedade camponesa está alicerçada no núcleo familiar, o qual é elementar nas tomadas de decisão para solução dos problemas contextuais. Isso permite maior sustentação do equilíbrio da exploração agrícola e do volume de trabalho empregado, sendo decisivo na garantia da reprodução social. A participação da família na avaliação dos elementos pertencentes à esfera econômica tem como referência o balanço entre trabalho e consumo (CHAYANOV, 1981).

El productor campesino aumentará su esfuerzo sólo si tiene razones para creer que así obtendrá un producto mayor que podrá destinar al aumento de la inversión o el consumo, pero no lleva el esfuerzo más allá del punto en que el posible aumento del producto es superado por lo desagradable del trabajo adicional. Por eso se ha llamado equilibrio trabajo-consumo a este mecanismo social. Chayanov demostró que para familias distintas el balance entre la satisfacción del consumidor y la molestia involucrada es afectado por el tamaño de la familia y la razón de los miembros que trabajan a los que no trabajan (KERBLAY, 1979, p. 136).

\footnotetext{
${ }^{4}$ Essa abordagem está presente nos estudos da História Cultural, como um paradigma científico de análise da realidade social. Para ela, a cultura é uma construção social, que deve ser decifrada a partir das significações que os sujeitos dão de si próprios e do contexto que estão inseridos. "A história cultural, tal como a entendemos, tem por principal objeto identificar o modo como em diferentes lugares e momentos uma determinada realidade social é construída, pensada, dada a ler" (CHARTIER, 1990, p. 16-17). Sobre o tema, cf. Hunt (1992).

5 "El proceso básico de transmisión de la cultura tradicional consiste en la educación, que introduce al novato a un mundo definido de valores materiales e inmateriales” (DOBROWOLSKI, 1979, p. 251).
} 
A lógica camponesa tem na família o elemento principal de operacionalização das atividades no espaço de produção. A unidade entre o consumo e a produção possibilitava uma integração das práticas e organização de estratégias adequadas às necessidades familiares e às condições da terra, do trabalho e dos instrumentos disponíveis. Essa racionalidade era orientada pelo ciclo demográfico da família, variável de acordo com o número de integrantes da unidade produtiva. A capacidade de trabalho e o volume da produção eram orientados por esse ciclo, considerando as condições básicas de reprodução do núcleo familiar.

De acordo com o equilíbrio produtivo na unidade familiar, era estabelecido o grau de auto-exploração do trabalho, não intensificado para além desse equilíbrio. Nessa perspectiva, o camponês conformava seus arranjos de acordo com elementos distintos da economia de mercado. A condição de existência do campesinato era a reprodução da unidade doméstica, e não a obtenção de renda e lucro. Esse produtor se integrava ao mercado de forma bastante incipiente por meio do excedente do consumo familiar. Isso não interessava ao sistema capitalista, tampouco ao Estado que assumia compromisso de financiar a tecnificação/modernização da agricultura via modelo desenvolvimentista.

$\mathrm{Na}$ economia capitalista, a organização da produção, regida externamente pela dinâmica imposta pelo mercado, requer intensificação e inovação técnica, com objetivo da geração de lucro. De modo geral, o camponês possuía autonomia na organização do processo de produção, condicionado ao balanço trabalho-consumo e às características culturalmente definidas e consolidadas. A lógica de produção camponesa baseava-se nas experiências de organização da unidade econômica, orientadas tradicionalmente. “Otro factor social menos importante, pero esencial, es el nivel de vida tradicional, impuesto por las costumbres y el hábito, que determina la amplitud de las pretensiones de consumo y, por ende, el empeño de la capacidad de trabajo" (CHAYANOV, 1981, p. $61)$.

A distinção entre a atividade econômica camponesa e o padrão capitalista de produção está baseada no retorno financeiro das práticas agrícolas. São lógicas de desenvolvimento opostas, organizadas por elementos diferenciados - economia camponesa, internos, e economia capitalista, externos - que garantem suas especificidades e articulações com determinados cenários. 
O aumento da produção, sua diversificação, a melhoria dos equipamentos produtivos, o impacto dos programas de assistência e formação na mudança de mentalidade beneficiariam forçosamente os dois parceiros: o pequeno agricultor veria sua renda aumentar, o Estado veria crescer as possibilidades de arrecadação de um excedente agrícola gerado por uma produção e uma produtividade aumentadas (SCHWARZ, 1990, p. 80).

A inserção do camponês na rota comercial acarretou inúmeras mudanças na forma de produzir, pois sua lógica contradizia as práticas adotadas pelo Estado.

Em um país em desenvolvimento ou recentemente industrializado, o Estado com sua burocracia do desenvolvimento e o mundo do agricultor tradicional pertencem a duas lógicas de reprodução diferentes. Nesse caso, é necessário identificar os elementos constituintes dessas lógicas e o seu modo de funcionamento, para melhor apreender suas naturezas fundamentalmente diferentes. É no funcionamento das contradições, nesse nível fundamental da reprodução dos sistemas, que a realidade problemática e contestada de um desenvolvimento agrícola sob tutela estatal pode tomar toda sua significação (SCHWARZ, 1990, p. 81).

Enquanto o Estado buscava aumentar o excedente da produção através da disseminação de práticas agrícolas orientadas à produção em larga escala (produtos para a agroindústria e exportação) e a integração nos CAIs, o campesinato direcionava seus esforços para as atividades de subsistência (segurança alimentar e reprodução da força de trabalho).

Assim, a lógica do sistema de reprodução da sociedade agrícola tradicional não pressiona necessariamente o agricultor a maximizar sua produção e sua renda. Ele vai, de preferência, procurar otimizar a utilização da sua força de trabalho, de maneira que o funcionamento do seu sistema de reprodução física, técnica, econômica, social e cultural seja garantido com a maior segurança possível (SCHWARZ, 1990, p. 90).

Dentro da modernidade técnica e industrial propagada pelo Estado, esse sistema de produção não teria conexão com a economia mercantil. Nesse sentido, a extensão rural teve um papel fundamental para desarticular a lógica de produção camponesa em nome do progresso técnico-científico.

Hoje percebe-se que a "Revolução Verde" deixou para o Estado e para a sociedade quatro passivos que indicam insustentabilidade: o passivo econômico, com endividamento agrícola e concentração de riqueza; o passivo social, aumentando a 
exclusão social, ampliação da miséria e da pobreza; o passivo ambiental, com a degradação de rios pelo uso intensivo de agroquímicos, pela erosão, pelo desmatamento e ocupação de grande extensão do Cerrado, do Pantanal e de parte significativa da Amazônia brasileira; e o passivo cultural, que suprimiu a cultura camponesa.

Assim, a tentativa de transformar o camponês em empresário rural acarretou em inúmeras mudanças na forma de produzir, pois a lógica camponesa contradizia as práticas adotadas pelo Estado para atender aos interesses do mercado. Estavam em jogo dois saberes diferenciados: o científico e o tradicional; dois projetos de sociedade: um, independente e endógeno; outro, dependente, elitista e industrial.

\begin{abstract}
As percepções do social não são de forma alguma discursos neutros: produzem estratégias e práticas (sociais, escolares, políticas) que tendem a impor uma autoridade à custa de outros, por elas menosprezados, a legitimar um projeto reformador ou a justificar, para os próprios indivíduos, as suas escolhas e condutas. Por isso esta investigação sobre as representações supõe-nas como estando sempre colocadas num campo de concorrências e competições cujos desafios se enunciam em termos de poder e dominação (CHARTIER, 1990, p. 17)
\end{abstract}

A disputa entre diferentes grupos, tentando impor projetos de sociedade (e o conjunto de elementos sociais próprios) desenvolve-se, também, nas lutas de representações. No conflito desses dois projetos contraditórios, ocorreram diversas transformações, prevalecendo, em grande proporção, a imposição das políticas governamentais atreladas aos interesses do capital. As representações divergentes são palco de resistências e rupturas, em que a imposição de novas formas de relações está permeada com conteúdo de legitimação de uma forma de dominação. No entremeio das disputas de representações, o domínio da lógica desenvolvimentista estatal era evidente. Com isso, o padrão hegemônico de produção, adotado nas grandes propriedades, deveria ser aplicado na agricultura camponesa.

Esses pacotes tecnológicos, tecnicamente inadaptados às pequenas propriedades, serviam para colocá-las em situação econômica desfavorável, provocando progressivamente a sua marginalização. [...] Esse fenômeno da marginalização dá origem a todo um processo sócio-econômico de empobrecimento do agricultor tradicional, que encontrará cada vez mais dificuldades para garantir a reprodução biológica, econômica e social de sua vida e de sua base produtiva, durante o ciclo repetitivo do processo de produção agrícola. [...] $\mathrm{Na}$ ausência total de segurança alimentar, instala na coletividade agrícola a fome generalizada estrutural, a pauperização e a 
proletarização que estimulam seguramente o êxodo rural (SCHWARZ, 1990, p. $110 ; 87 ; 89)$.

A situação de pobreza, as condições degradantes de trabalho, o êxodo rural e a consequente marginalização social, evidenciavam que os programas e projetos agrícolas governamentais, em sua origem, foram concebidos com a total ausência da incorporação da massa camponesa e suas particularidades (organização cultural e econômica). A lógica capitalista, assumida pelo Estado, foi determinante para desagregação do campesinato e fragmentação de seu saber e lógica de produção.

\section{Os impactos na produção camponesa}

As consequências da modernização conservadora não se resumiram no empobrecimento e exclusão dos camponeses. Abrangeram, também, outras questões. Além da repressão aos movimentos sociais de luta pela reforma agrária, mobilizados politicamente nos anos 1960, o regime militar organizou meios jurídicos para redimensionar a política de reforma agrária no Brasil. Apesar da aprovação do Estatuto da Terra (Lei 4.504, de 30 de novembro de 1964), a reforma agrária foi articulada com a colonização dirigida na região amazônica e de Cerrado. Esse programa constituiu-se numa verdadeira "contra-reforma", pois todo o processo era tutelado e financiado pelo Estado, e realizado pela iniciativa privada, que mantinha o controle da questão fundiária por meio de um discurso desenvolvimentista.

Em nome da geração de empregos e expansão do mercado consumidor de insumos e máquinas industrializadas, o regime militar impediu a política de reforma agrária nas principais regiões do país, para instituir um novo projeto: a abertura da nova fronteira agrícola no Centro-Oeste e a colonização da região Norte do Brasil. Esse processo enfraqueceu temporariamente as lutas sociais, que voltaram à cena no final da década de 1970, demonstrando a falibilidade da colonização dirigida e implantada pelos governos militares. A falência desse modelo aprofundou o problema da concentração fundiária, pois muitos agricultores e camponeses que compraram terras nessas regiões, ou foram contemplados por títulos do Estado, investiram suas economias para a abertura de novas áreas, mas não tinham como 
escoar e vender a produção. Isso resultou em endividamento. Sem crédito muitos agricultores abandonaram suas propriedades, que foram absorvidas pelos produtores de maior poder aquisitivo.

A "modernização conservadora" foi extremamente excludente e contribuiu para a reprodução das relações de dominação e de exploração do trabalho no campo (GRAZIANO DA SILVA, 1982). O trabalhador rural, agente de todo processo de produção na terra em que vivia (como meeiro, colono, proprietário, etc.), passava a ser um proletário inserido nos CAIs. "[...] vislumbra-se na lógica e nas contradições que emergiram da ação modernizante uma configuração de novos personagens, que [...] tiveram origem na aurora do processo de modernização no campo" (BASSANI, 2006, p. 43).

O êxodo rural, decorrente da exclusão social da modernização da agricultura, aliado à precarização da pequena propriedade rural, foram responsáveis pelo surgimento de uma nova categoria de trabalhador: o Assalariado Rural Temporário (ART) ou "bóia-fria".

O ART designa que é tão somente proprietário de sua força de trabalho, não possuindo meios de produção, isto é, capital e terra. Nessa condição, ele se encontra determinado a transformar em mercadoria sua força de trabalho e vendê-la no mercado, especialmente prestando trabalhos rurais, porém não descartando outras atividades. Dessa relação, ele busca obter como pagamento pelo uso de sua força de trabalho os bens necessários para sua sobrevivência. Essa venda de força de trabalho em atividades temporárias constitui a condição econômica básica da vida desse trabalhador (BASSANI, 2006, p. 14).

Este trabalhador temporário, residente na periferia dos grandes centros urbanos, vilas, distritos ou em pequenas propriedades, vivia em situação de instabilidade referente à sua subsistência familiar, devido ao caráter intermitente de seu trabalho. A necessidade de emprego, num cenário precário de crescente miserabilidade e abundância na oferta de mão-de-obra, fazia com que o "bóia-fria" se submetesse à condições sub-humanas de trabalho no manejo de máquinas, no plantio ou na colheita (D'INCAO, 1975).

O caráter excludente da modernização da agricultura agravou as condições de vida, tanto no meio rural como nos grandes centros urbanos. No contexto da 
"redemocratização", esses marginalizados foram os protagonistas da organização de diversos movimentos sociais de lutas por direitos políticos, por moradia, pela reforma agrária ${ }^{6}$, entre outros que redefiniram novas formas de mobilização.

\section{Na crise surgem alternativas: a perspectiva da agroecologia}

Os debates contemporâneos sobre a questão agrária no Brasil não podem ser dissociados da noção de sustentabilidade ou de desenvolvimento sustentável. Agricultura sustentável refere-se a “[...] um modelo de organização social e econômica baseado em um desenvolvimento equitativo e participativo. [...] A agricultura é sustentável quando é ecologicamente equilibrada, economicamente viável, socialmente justa, culturalmente apropriada e fundamentada em um conhecimento holístico" (ATSA ${ }^{7}$, apud EHLERS, 1996, p. 117).

Nessa perspectiva conceitual de sustentabilidade, a transição da agricultura moderna industrial para diversificados estilos de agricultura sustentável está intimamente relacionada ao desenvolvimento de uma nova ciência, imbuída de princípios e práticas que visam à construção de um novo paradigma de produção. Um paradigma emergente que se constitui numa nova epistemologia, a qual valorize a técnica e a coloque a favor da vida, e se apóie nos saberes tradicionais. Uma ciência competente para religar os saberes técnico-científicos ao conhecimento popular, à natureza e à cultura.

\footnotetext{
A Agroecologia proporciona o conhecimento e a metodologia necessários para desenvolver uma agricultura que é ambientalmente consciente, altamente produtiva e economicamente viável. Ela abre a porta para o desenvolvimento de novos paradigmas da agricultura, em parte porque corta pela raiz a distinção entre a produção de conhecimento e sua aplicação. Valoriza o conhecimento local e empírico dos agricultores, a socialização desse conhecimento e sua aplicação ao objetivo comum da sustentabilidade (GLIESSMAN, 2000, p. 54).
}

\footnotetext{
${ }^{6}$ A relação entre os ART ("bóia-fria") e o MST, por exemplo, estaria mais próxima a partir do crescimento do movimento de luta pela terra nos anos 90. "O vínculo crescente do ART com a luta pela terra tornou-se um fenômeno visível, sendo muitos os relatos e depoimentos que associam os ART aos acampamentos do MST [...]" (BASSANI, 2006, p. 126).

${ }^{7}$ Alternative Treaty on Sustenaible Agriculture (Tratado Alternativo sobre Agricultura Sustentável).
} 
A agroecologia se mostra competente para promover não só a ciência, mas novas relações sociais e culturais no campo. Essa base científico-tecnológica visa, essencialmente, produzir um novo modo de relacionamento do homem com meio ambiente, através de práticas que proporcionem um desenvolvimento abrangente da sustentabilidade (ALTIERI, 1999). Isso demonstra que a modernização técnica pode percorrer um caminho diferente, incorporando dimensões econômicas, sociais, culturais e ambientais, que podem alavancar um novo processo rumo a uma agricultura de base ecológica.

O termo agroecologia vem sendo usado desde os anos 1970, porém sua prática pode ser resgatada desde as origens da agricultura. Os saberes agrícolas de indígenas e camponeses, através da relação direta com elementos objetivos e subjetivos, regulavam a produção de acordo com os conhecimentos acumulados e as necessidades imediatas de consumo. "As práticas agroecológicas nos remetem à recuperação dos saberes tradicionais, a um passado no qual o humano era dono do seu saber, a um tempo em que seu saber marcava um lugar no mundo e um sentido da existência" (LEFF, 2002, p. 36). A agricultura campesina sempre foi pautada por uma lógica própria interna de funcionamento, baseada na tradição e na transmissão de conhecimentos populares ${ }^{8}$.

La agroecologia há surgido como un enfoque nuevo al desarrollo agrícola más sensible a las complejidades de las agriculturas locales, al ampliar los objetivos y critérios de agrícolas para abarcar proriedades de sustentabilidade, seguridad alimentaria, estabilidad biológica, conservación de los recursos u equidade junto con el objetivo de uma mayor producción (ALTIERI; YURJEVIC, 1991, p. 33).

A agroecologia surge como uma ciência pautada por conceitos, princípios e metodologias, que buscam a autonomia dos trabalhadores rurais marginalizados pela exploração da agricultura moderna. Por associar as questões ambientais, sociais, econômicas e organizativas, a agroecologia incorpora e amplia outras dimensões da prática agrícola, buscando no saber tradicional (camponês e indígena) os princípios para a construção de novos conhecimentos, tendo a tecnologia social como uma aliada (SEVILLA GUZMÁN, 2001).

\footnotetext{
${ }^{8}$ O processo histórico de acumulação capitalista no Brasil desarticulou esses conhecimentos, gerando uma padronização construída de fora para dentro. Os saberes tradicionais foram marginalizados pelo produtivismo e pela lógica do mercado, condição da agricultura moderna.
} 
Guivant (1997) afirma que a análise sobre agroecologia e desenvolvimento sustentável não deve reproduzir a mesma dicotomia da agricultura moderna, estabelecendo uma conceituação sobre conhecimento local, participativo e holístico, que se opõe ao conhecimento científico da agricultura moderna (difusionista, parcial e predatório). Segundo a autora, a base epistemológica e política da agroecologia é resultado de um conjunto de processos, os quais passam a constituir um conhecimento heterogêneo, que dá significado local às tecnologias disponíveis. Seguindo esse princípio, seriam redefinidas as relações entre conhecimento científico e conhecimento local no desenvolvimento de uma agricultura sustentável.

A agroecologia se apresenta como a principal alternativa para a transição da agricultura convencional e degradante, para uma agricultura ecológica baseada nos princípios da sustentabilidade. Esse pressuposto deve considerar diferentes dimensões, que articuladas, orientam a busca crescente do desenvolvimento sustentável.

[...] a construção do desenvolvimento rural sustentável, a partir da aplicação dos princípios da Agroecologia, deve assentar-se na busca de contextos de sustentabilidade crescente, alicerçados em algumas dimensões básicas. [...] entendemos que as estratégias orientadas à promoção da agricultura e do desenvolvimento rural sustentáveis devem ter em conta seis dimensões relacionadas entre si, quais sejam: ecológica, econômica, social (primeiro nível), cultural, política (segundo nível) e ética (terceiro nível) (CAPORAL; COSTABEBER, 2002, p. 76).

A agroecologia assume um papel potencializador na mudança da matriz de produção moderna, inserindo viés social e ambiental no processo. Isso se reflete na alteração das práticas produtivas, ou melhor, na conversão para agroecossistemas sustentáveis. A transição da agricultura convencional, erguida sobre pilares econômicos, para a agricultura ecológica é um processo a médio e longo prazo, que assimila técnicas e princípios coerentes com autonomia, estabilidade, produtividade e qualidade de vida dos agricultores.

Como propósito mais geral, está a passagem dos atuais padrões de desenvolvimento rural ou de sistemas de produção de baixa sustentabilidade para modelos de agricultura e de manejo rural que privilegiem e incorporem princípios, métodos e tecnologias de base ecológica. Isso implica não somente a busca de maior racionalização produtiva com base nas especificidades biofísicas de cada agroecossistema, mas também uma mudança nas atitudes e valores dos atores sociais em relação ao manejo e conservação dos recursos. A Agroecologia, como campo de estudos de caráter multidisciplinar, integra e articula conhecimentos de diferentes ciências, assim como saberes populares, permitindo justamente que se 
construam estratégias e condições para apoiar esse processo de transformação, tendo-se como referência os ideais da sustentabilidade a médio e longo prazos (COSTABEBER, 2006, p. 04).

Segundo Costabeber (2006), a transição agroecológica é um processo lento e gradual, imbuído pela mudança de valores e inserção das famílias e das comunidades na construção de alternativas viáveis para a localidade. A conversão da base produtiva deve ter um caráter participativo nas decisões sobre a melhoria das condições sócioeconômicas e ambientais. Isso é possível devido ao reconhecimento da diversidade social, cultural e ecológica das localidades.

A Agroecologia, que propõe o desenho de métodos de desenvolvimento endógeno para o manejo ecológico dos recursos naturais, necessita utilizar, na maior medida possível, os elementos de resistência específicos de cada identidade local. [...] Se trata, pois, de criar e avaliar tecnologias autóctones, articuladas com tecnologias externas que, mediante o ensaio e a adaptação, possam ser incorporadas ao acervo cultural dos saberes e ao sistema de valores próprio de cada comunidade (SEVILLA GUZMÁN, 2001, p. 36-37).

Para que a transição agroecológica seja bem-sucedida, é preciso integrar esforços que visem ao avanço tecnológico e à ampliação das esferas participativas locais. "Quando as respostas são adequadas à localidade (comunidade) e a suas condições concretas e específicas, se produz a geração de um potencial endógeno, evidenciando as próprias possibilidades e limitações” (SEVILLA GUZMÁN, 2001, p. 41). A interação com os conhecimentos locais permite maiores condições de rompimento dos limites práticos da transição agroecológica.

O conhecimento local é necessário para a mudança gradual das referências tecnológicas e culturais produzidas e reproduzidas pela modernização da agricultura. Para ultrapassar cada etapa de mudança nas práticas e relações, é importante estabelecer um processo multidimensional, que ultrapasse a orientação econômica da produção (voltada para atender ao mercado) e abra espaço para as dimensões social e ambiental.

Segundo Costabeber e Moyano (2000), a transição agroecológica está se desenvolvendo impulsionada por dois processos complementares: a ecologização e ação coletiva. O primeiro representa a mudança das práticas agrícolas mediante a substituição de recursos externos (insumos químicos e equipamentos), a adequação aos ciclos naturais do agroecossistema e a incorporação de tecnologias "verdes" para manejo da produção. O segundo está associado à adesão de produtores à agroecologia enquanto 
projeto coletivo, visando os interesses sociais compartilhados e a mudança de valores em torno de uma alternativa para o contexto local.

Devido a essa questão, alguns limites são impostos no processo, constituindo-se desafios a serem superados ${ }^{9}$.

Uma vez mais, a atual condição de marginalização e exclusão de certos grupos sociais e a necessidade urgente que há em se obter resultados no plano da reprodução social constituem fatores que jogam contra a capacidade de afirmação dessas novas idéias [...] (ALMEIDA, 1998, p. 242).

Pela carência dos agricultores afetados pela modernização da agricultura, soluções de médio e longo prazo podem encontrar resistência, devido às necessidades imediatas de melhoria das condições sócio-econômicas ${ }^{10}$. Além da dimensão econômica, podem ser destacadas outras dificuldades relativas à conversão da matriz tecnológica de produção: a) a operacionalidade do trabalho; b) o conhecimento técnico de como produzir; c) a produção em escala ampliada.

Devido a essas limitações, a produção agroecológica no país está, em sua maioria, em processo de avaliação e aperfeiçoamento, apesar do avanço do cultivo de orgânicos na última década. Segundo Darolt (2001), em dez anos a área cultivada de produtos orgânicos no Brasil foi elevada em quase $1.000 \%$, chegando, no início da década passada a cerca de 100.000 ha plantados. No final do mesmo decênio, a produção brasileira estava estimada em 889.000 ha (WILLER; YUSSEFI; SORENSEN, 2008). Isso significou a inserção do Brasil entre os dez maiores produtores do mundo.

Tabela 1: Ranking dos maiores produtores mundiais de orgânicos.

\begin{tabular}{|c|c|c|}
\hline RANKING & PAÍSES & HECTARES CULTIVADOS \\
\hline 01 & Austrália & 12.300 .000 ha \\
\hline 02 & China & 2.300 .000 ha \\
\hline 03 & Argentina & 2.200 .000 ha \\
\hline 03 & Estados Unidos & 1.600 .000 ha \\
\hline 05 & Itália & 1.100 .000 ha \\
\hline 06 & Uruguai & 900.000 ha \\
\hline 07 & Espanha & 900.000 ha \\
\hline
\end{tabular}

\footnotetext{
${ }^{9}$ A transição agroecológica exige um encadeamento de ações, que, no Brasil, ainda está em fase inicial. As iniciativas de maior destaque estão localizadas no Rio Grande do Sul, através dos trabalhos da EMATER/ASCAR do Estado.

${ }^{10}$ Essas condições estão associadas, também, à reconstrução ativa do mercado local (feiras, rede de consumidores "conscientes", supermercados, etc.). Os produtos agroecológicos devem ser inseridos em circuitos mercantis (curtos e longos), viabilizando economicamente a produção.
} 


\begin{tabular}{|c|c|c|}
\hline 08 & Brasil & 889.000 ha \\
\hline 09 & Alemanha & 800.000 ha \\
\hline 10 & Reino Unido & 600.000 ha \\
\hline
\end{tabular}

Fonte: IFOAM (WILLER; YUSSEFI; SORENSEN, 2008).

Mesmo com esses números, produção orgânica não é o mesmo que produção agroecológica. A expansão do cultivo de orgânicos não significa o avanço da agricultura sustentável em suas múltiplas dimensões. Os compromissos ambiental e social estão subordinados ao aumento da demanda de consumidores, principalmente, nos Estados Unidos e na Europa por produtos sem agrotóxicos, ou seja, a lógica econômica impulsiona a abertura de novas áreas de cultivo no Brasil. Segundo o MDA, estima-se que do total de ha destinados à produção orgânica, apenas 25.000 são agroecológicos $(2,8 \%)$ (BRASIL, 2010).

\begin{abstract}
A título de exemplo, não podemos, simplesmente, entender a agricultura agroecológica como aquela agricultura que não utiliza agrotóxicos ou fertilizantes químicos de síntese em seu processo produtivo. No limite, uma agricultura com esta característica pode corresponder a uma agricultura pobre, desprotegida, cujos praticantes não têm ou não tiveram acesso aos insumos modernos por impossibilidade econômica, por falta de informação ou por ausência de políticas públicas adequadas para este fim. Ademais, opção desta natureza pode estar justificada por uma visão estratégica de conquistar mercados cativos ou nichos de mercado que, dado o grau de informação que possuem alguns segmentos dos consumidores a respeito dos riscos embutidos nos produtos da agricultura convencional, supervalorizam economicamente os produtos ditos 'ecológicos', 'orgânicos' ou 'limpos', o que não necessariamente assegura a sustentabilidade dos sistemas agrícolas através do tempo (CAPORAL; COSTABEBER, 2002, p. 74).
\end{abstract}

A agroecologia propõe a construção de uma agricultura de base sustentável, com segurança alimentar e geração de renda. Dessa forma, o aumento da produção, articulado aos princípios de desenvolvimento endógeno, vem sendo apoiado por políticas que incentivam a mudança da matriz tecnológica e proporcionam ferramentas técnicas para a aplicabilidade nas localidades. O papel das políticas é fundamental para o processo, seja através da mudança no paradigma extensionista, seja pelo incremento de crédito e disseminação de tecnologia social.

A chamada "Extensão Rural Agroecológica" vem sendo construída com o objetivo de buscar, junto às populações rurais, a formação de contextos de sustentabilidade, para resgatar a autonomia dos trabalhadores e recuperar formas de organização e saber local. 
Em 2004, o Governo Federal elaborou a Política Nacional de Assistência Técnica e Extensão Rural (PNATER), sob responsabilidade do Ministério do Desenvolvimento Agrário (MDA) ${ }^{11}$. A PNATER ${ }^{12}$ foi construída através de uma articulação de instituições públicas, organizações civis, movimentos sociais e lideranças de organizações de agricultores familiares. "Essa Política pretende contribuir para uma ação institucional capaz de implantar e consolidar estratégias de desenvolvimento rural sustentável [...]” (BRASIL, 2004, p. 03). Dentre seus princípios está o rompimento com o modelo extensionista baseado na difusão do conhecimento e nos pacotes da Revolução Verde e a adoção da agroecologia como paradigma tecnológico. Segundo o documento, as atividades de assistência técnica e extensão rural devem partir da análise dos diferentes agroecossistemas, da diversidade cultural e condições socioeconômicas, devendo desempenhar o papel de facilitadores através de metodologias participativas.

[...] as ações da Ater devem privilegiar o potencial endógeno das comunidades e territórios, resgatar e interagir com os conhecimentos dos agricultores familiares e demais povos que vivem e trabalham no campo em regime de economia familiar, e estimular o uso sustentável dos recursos locais (BRASIL, 2004, p. 07).

O objetivo geral da PNATER tem como eixo orientador das ações a agroecologia, potencializadora do desenvolvimento sustentável no meio rural. Essa referência é a base de formação dos agentes (extensionistas e assessores técnicos) para a transição agroecológica em contextos locais ${ }^{13}$.

Em relação às linhas de crédito, a situação adquiriu novos contornos nos últimos anos. As políticas de financiamento, que articulavam os recursos à utilização de insumos modernos (crédito de custeio), além de vincular a compra de máquinas (destinadas à produção) ao "receituário" dos pacotes tecnológicos (crédito de investimento), foram relativamente flexibilizadas com a inserção de uma nova

\footnotetext{
${ }^{11}$ O Departamento de Assistência Técnica e Extensão Rural (DATER) foi transferido para o Ministério do Desenvolvimento Agrário em 2003, através do Decreto $\mathrm{N}^{\circ}$ 4.739. No mesmo ano foi criado um grupo de trabalho para coordenar a elaboração da PNATER.

${ }^{12}$ Em consonância com as políticas que vêm sendo desenvolvidas, recentemente foi instituído, através da Lei Federal $N^{\circ} 12.188 / 2010$, o Programa Nacional de Assistência Técnica e Extensão Rural na Agricultura Familiar e na Reforma Agrária (PRONATER), que foi concebido como instrumento de implementação da PNATER.

${ }^{13}$ De acordo com o MDA, existem mais de 100 cursos de agroecologia no País. Somente neste final de ano serão disponibilizados R \$ 16.200.000,00 em convênio com o Conselho Nacional de Desenvolvimento Científico e Tecnológico (CNPq), para formação de 56 Núcleos de Pesquisa e Extensão em Agroecologia em instituições de ensino superior (BRASIL, 2010a).
} 
modalidade dentro do Programa Nacional de Apoio a Agricultura Familiar (PRONAF). A produção ecológica, que não encontrava meios de obter crédito, foi "beneficiada", em 2003, com a criação do PRONAF Agroecologia.

Para operar o Pronaf Agroecologia, por exemplo, os agricultores que tencionavam o crédito foram obrigados a apresentar projetos de conversão das propriedades que tivessem a duração de três anos. Nesses projetos, deveriam estar claramente indicadas, ano a ano, as etapas de substituição de práticas convencionais por práticas agroecológicas (WEID, 2006, p. 20).

Apesar dessa inovação, as exigências governamentais obrigavam os agricultores a apresentar um planejamento de transição a curto prazo, o que não é compatível com os elementos de conversão agroecológica. Isso dificultou o acesso ao crédito por grande parte dos produtores, os quais não conseguiram atender as condições de financiamento ${ }^{14}$

Uma iniciativa que vem ganhando visibilidade é a parceria entre o Ministério do Desenvolvimento Social e Combate à Fome (MDS) e a Fundação Banco do Brasil (FBB). Ela consiste na "Tecnologia Social PAIS” (Produção Agroecológica Integrada e Sustentável), voltada para a agricultura familiar, como uma alternativa para geração de trabalho e renda. A tecnologia é baseada em três diretrizes fundamentais:

É agroecológica porque dispensa o uso de ações danosas ao meio ambiente, como o emprego de agrotóxicos (adubo e veneno), queimadas e desmatamentos.

É integrada porque alia a criação de animais com a produção vegetal e ainda utiliza insumos da propriedade em todo o processo produtivo.

É sustentável porque preserva a qualidade do solo e das fontes de água, incentiva o associativismo dos produtores e aponta novos canais de comercialização dos produtos, permitindo boas colheitas agora e no futuro (PAIS, 2008, p. 06, grifo no documento).

O PAIS é um sistema de produção organizado em círculo, formado por um galinheiro no centro, canteiros para produção no entorno e irrigação por gotejamento através de reservatório elevado. Tem como premissa o cultivo de alimentos mais saudáveis, tanto para o consumo próprio quanto para a comercialização de excedentes (PAIS, 2008).

\footnotetext{
${ }^{14}$ Mesmo com essas dificuldades, o PRONAF Agroecologia ainda é contemplado nos Plano Safra da Agricultura Familiar. No Plano 2010/2011, o financiamento para a conversão produtiva pode chegar a 50 mil reais por estabelecimento agrícola familiar.
} 
Com o apoio do MDS, foram implantadas, entre participantes de programas sociais do governo federal, mais de 2 mil unidades do PAIS em 14 estados. A tecnologia social vem sendo entendida como uma importante alternativa para trabalhadores rurais com vulnerabilidade alimentar e financeira, também, como forma de disseminar um estilo de desenvolvimento mais sensível com o meio ambiente (BRASIL, 2010b).

A criação de políticas públicas e aumento do aporte de recursos para a transição agroecológica demonstram como esse modelo de produção vem ganhando espaço entre camponeses e agricultores familiares no país. Além disso, a agroecologia representa um novo projeto de sociedade, incorporado por movimentos sociais para contestação do modelo político-econômico capitalista.

\section{Considerações Finais}

As mudanças nas bases técnicas, por meio da introdução de máquinas e insumos químicos produzidos na indústria, foram fundamentais para consolidar a modernização da agricultura brasileira. Em seu bojo, os problemas sociais foram se agravando no meio rural. O projeto de desenvolvimento adotado pelo Estado impôs uma lógica contraditória à agricultura tradicional no país. Grande parte dos agricultores, que não se integraram ao mercado, passou a se proletarizar nas grandes fazendas na forma de trabalhadores temporários ("bóia-fria").

O conflito entre duas lógicas de desenvolvimento evidenciou os limites e contradições do padrão produtivista de produção. Diante da crise cultural, ambiental e política desse modelo, a agroecologia se apresenta como uma alternativa, uma ciência e tecnologia social disponível aos camponeses, agricultores familiares, consumidores e sujeitos engajados em projetos de mudança social.

A transição da agricultura convencional, erguida sobre pilares econômicos, para a agricultura ecológica, é um processo a médio e longo prazo, que assimila técnicas e princípios coerentes com autonomia, estabilidade, produtividade e qualidade de vida dos agricultores e dos consumidores. A agroecologia não busca o retorno a um passado, mas sim estabelecer elos com o processo produtivo tradicional, distanciando-se pragmática e paradigmaticamente da agricultura produtivista. 
Para que a transição agroecológica seja bem-sucedida é preciso integrar esforços que visem a formulação de políticas públicas, o avanço tecnológico e a ampliação das esferas participativas locais. Estratégias importantes para essa relação são a contextualização e a apreensão da diversidade sócio-cultural-ecológica-humana. Nesse sentido, deve-se buscar um enfoque endógeno, considerando a grande heterogeneidade existente.

\section{Referências}

ALMEIDA, Jalcione. A problemática do desenvolvimento sustentável. In: BECKER, Dinizar F. (Org). Desenvolvimento sustentável: necessidade e/ou possibilidade? Santa Cruz do Sul: EDUNISC, 1997.

Significados sociais, desafios e potencialidades da agroecologia. In: BRANDENBURG, Alfio; FERREIRA, Ângela D. D. (Orgs) Para pensar outra agricultura. Curitiba: Editora da UFPR, 1998. p. 239-247.

ALTIERI, Miguel. A. \& YURJEVIC, Andrés. La Agroecologia y el desarollo en América Latina. In: Agroecologia y Desarollo. Revista del CLADES, año I, nº I, p. 2536, marzo, 1991.

ALTIERI, Miguel. Agroecología: bases científicas para una agricultura sustentable. Montevideo: Editorial Nordan-Comunidad, 1999.

BASSANI, Paulo. Trabalhadores rurais: resistência e descoberta. Londrina: EDUEL, 2006.

BRASIL. Política Nacional de Assistência Técnica e Extensão Rural. Brasília: Ministério do Desenvolvimento Agrário/Secretaria da Agricultura Familiar, 2004.

Ministério do Desenvolvimento Agrário/Secretaria da Agricultura Familiar. Produção agroecológica. Disponível em: <http://www.mda.gov.br/portal/saf/publicações>. Acesso em: 12 nov. 2010.

Ministério do Desenvolvimento Agrário/Secretaria da Agricultura Familiar. Formação de agentes de Ater. Disponível em: <http://www.mda.gov.br/portal/saf/institucional/assistenciatecnicaextensaorural $>$. Acesso em: 12 nov. 2010a.

Ministério do Desenvolvimento Social e Combate à Fome. Produção agroecológica já está presente em 19 Estados. Disponível em: <http://www.mds.gov.br/noticias/>. Acesso em: 12 nov. $2010 \mathrm{~b}$. 
BRUM, Argemiro J. Modernização da agricultura: trigo e soja. Ijuí, RS: Fidene, 1985.

CAPORAL, Francisco R.; COSTABEBER, José A. A extensão rural no Rio Grande do Sul: da tradição "Made in USA" ao paradigma agroecológico. Porto Alegre: EMATER/RS, 2001.

Análise multidimensional da sustentabilidade: uma proposta metodológica a partir da agroecologia. Agroecologia e Desenvolvimento Rural Sustentável, Porto Alegre, vol. 3, n 3, p. 70-85, jul/set, 2002.

CHARTIER, Roger. A História Cultural: entre práticas e representações. Lisboa-Rio de Janeiro: Difel/Bertrand Brasil, 1990.

CHAYANOV, Alexandr V. Sobre la teoria de los sistemas económicos no capitalistas. Cuadernos de Pasado y Presente. México: Siglo XXI Editores, 1981.

COSTABEBER, José A.; MOYANO, Eduardo. Transição agroecológica e ação social coletiva. Agroecologia e Desenvolvimento Rural Sustentável, Porto Alegre, vol. 1, no 4, p. 50-60, out/dez, 2000.

COSTABEBER, José A. Transição agroecológica: rumo à sustentabilidade. Agriculturas, Rio de Janeiro, vol. 3, n 3, p. 04-05, out, 2006.

DAROLT, Moacir R. Estado e característica atual da agricultura orgânica no mundo. Revista Brasileira de Agropecuária, v. 1, n. 9, p. 44-48, 2001.

D’ INCAO, Maria C. O bóia fria: acumulação e miséria. Petrópolis: Vozes, 1975.

DOBROWOLSKI, Kazimierz. La cultura campesina tradicional. In: SHANIN, Teodor (Org). Campesinos y sociedades campesinas. México: Fondo de Cultura Económica, 1979.

EHLERS, Eduardo. Agricultura sustentável: origens e perspectivas de um novo paradigma. São Paulo: Livros da Terra, 1996.

GUEVARA, Arnoldo J. H.; HOEFFEL, João L.; VIANA, Rosa M. As relações entre o natural e o artificial e suas implicações educacionais. In: GUEVARA, Arnoldo J. H.; HOEFFEL, João L.; VIANA, Rosa M.; D'AMBRÓSIO, Ubiratan (Orgs). Conhecimento, Cidadania e Meio Ambiente. Vol 2. São Paulo: Peirópolis, 1998.

GLIESSMAN, Sthephen R. Agroecologia: processos ecológicos em agricultura sustentável. Porto Alegre: Editora da UFRGS, 2000.

GRAZIANO DA SILVA, José. A modernização dolorosa: estrutura agrária, fronteira agrícola e trabalhadores rurais no Brasil. Rio de Janeiro: Zahar, 1982. 
1996.

A nova dinâmica da agricultura brasileira. Campinas, SP: UNICAMP/IE,

GUIVANT, Júlia S. Heterogeneidade de conhecimentos no desenvolvimento rural sustentável. Cadernos de Ciência \& Tecnologia, Brasília, vol. 14, n 3, p. 411-446, set/dez, 1997.

HUNT, Lynn. A nova história cultural. São Paulo: Martins Fontes, 1992. (O Homem e a História)

KAGEYAMA, Ângela, et al. O novo padrão agrícola brasileiro: do complexo rural aos complexos agroindustriais. In: Delgado, G. et al (Orgs). Agricultura e Políticas Públicas. Brasília: Ipea, 1990 (relatório no 127).

KERBLAY, Basile. Chayanov y la teoría del campesinado como un tipo específico de economía. In: SHANIN, Teodor (Org). Campesinos y sociedades campesinas. México: Fondo de Cultura Económica, 1979.

LEFF, Enrique. Agroecologia e saber ambiental. Agroecologia e Desenvolvimento Rural Sustentável, Porto Alegre, vol. 3, n 1, p. 36-51, jan/mar, 2002.

PAIS. Produção Agroecológica Integrada e Sustentável: mais alimento, trabalho e renda no campo. Brasília: Fundação Banco do Brasil, 2008.

PALMEIRA, Moacir. Modernização, Estado e Questão Agrária. Estudos Avançados, vol. 3, n. 7, p. 87-108, São Paulo Set./Dez., 1989.

SEVILLA GUZMÁN, Eduardo. Uma estratégia de sustentabilidade a partir da agroecologia. Agroecologia e Desenvolvimento Rural Sustentável, Porto Alegre, vol. $2, \mathrm{n}^{\mathrm{o}} 1$, p. 35-45, jan/mar, 2001.

SCHWARZ, Alf. Lógica do Desenvolvimento do Estado e Lógica Camponesa. Revista Tempo Social, São Paulo, p. 75-114, $1^{\circ}$ sem., 1990.

WEID, Jean M. A transição agroecológica das políticas de crédito voltadas para a agricultura familiar. Agriculturas, Rio de Janeiro, vol. 3, n 1, p. 18-20, abr, 2006.

WILLER Helga; YUSSEFI, Minou; SORENSEN, Neil (Eds). The world of organic agriculture. Statistics and emerging trends. Bonn: International Federation of Organic Movement (IFOAM); Research Institute of Organic Agriculture, 2008. Disponível em: <http://www.ifoam.org/>. Acesso em: 12 nov. 2010.

Recebido para publicação em setembro de 2010

Aprovado para publicação em dezembro de 2010 